\title{
INQUIETAÇÕES SOBRE EDUCAÇÃO E DEMOCRACIA EM TEMPOS DE PANDEMIA
}

\author{
Esmael Alves de Oliveira ${ }^{\mathrm{i}}$ \\ Aguinaldo Rodrigues Gomes ${ }^{\text {ii }}$ \\ Tatiane Pereira Muniz iii \\ Jorge Augusto de Jesus Silva ${ }^{\text {iv }}$
}

\begin{abstract}
Resumo
No presente ensaio, desde uma perspectiva transdisciplinar, objetivamos refletir sobre as dimensões político-sociais da pandemia de covid-19 no Brasil a partir dos marcadores sociais de diferença. Ao nos debruçarmos sobre os dilemas que envolvem a educação e a democracia no país, por meio da categoria "efeito colateral" e em diálogo com as reflexões de Arendt, Santos, Agamben e Mbembe, chegamos à conclusão de que as discussões sobre a pandemia não se reduzem a uma dimensão epidemiológica e/ou biomédica, antes, estão articuladas a complexas relações de saber-poder que expõem ainda mais a sua face violenta, racista, sexista e autoritária.
\end{abstract}

Palavras-chave: Covid-19. Marcadores sociais de diferença. Educação, Democracia.

\section{CONCERNS ABOUT EDUCATION AND DEMOCRACY IN PANDEMIC TIMES}

\begin{abstract}
In this essay we aim to reflect on social and politic dimensions of covid-19 pandemics in Brazil since an interdisciplinary view and considering social markers of difference. Drawing on dilemmas concerning Brazilian education and democracy, by means of "side effect" category, and dialoguing whith Arendt, Santos, Agamben e Mbembe, we conclude that debates about pandemic issues has to do not only with epidemiological or biomedical explanations, but are also articulated to power-knowledge relations complexities that further exposes its violent, racist, sexist and authoritarian face.
\end{abstract}

Keywords: Covid-19. Difference social markers. Education, Democracy.

\section{Introdução}

Este ensaio emerge da inquietação dos autores e da autora diante dos "efeitos colaterais"v vivenciados socialmente em decorrência da pandemia de covid-19. A partir de nossos lugares, docentes respectivamente na Universidade Federal da Grande Dourados (UFGD), Universidade Federal de Mato Grosso do Sul (UFMS), no Instituto Federal da Bahia (IFBA) e Instituto Federal Baiano (IFBaiano), desejamos refletir sobre algumas situações que temos visto, vivenciado e experimentado nesse tempo de crise.

Cabe ressaltar ainda que, por estarmos localizados em diferentes campos disciplinares (antropologia, letras e educação) e por privilegiarmos também outros saberes, nosso diálogo é pautado numa perspectiva transdisciplinar. Para nós está claro que o momento que vivemos não pode ser devidamente compreendido a partir de um único ponto de vista e/ou especialidade acadêmica. Antes, 
exige, e tem exigido desde o início de todos nós (docentes, discentes, pesquisadores, pesquisadoras, sociedade civil e governos, dentre outros) um exercício de descentramento, de trocas e de partilhas. Nesse sentido, acreditamos não ser possível uma abordagem sobre os efeitos colaterais da covid-19 sem uma discussão sobre a dimensão político-econômico-ideológica que a atravessa.

A partir disso é que nos centramos aqui na dimensão pública e política da educação, que tem a função de introduzir o novo num mundo pelo qual todos nós, jovens e adultos, temos responsabilidade. Hannah Arendt afirma que "a educação não pode desempenhar papel nenhum na política, pois na política lidamos com aqueles que já estão educados. Quem quer que queira educar adultos na realidade pretende agir como guardião e impedi-los de atividade política" (ARENDT, 2013, p. 225). Em que pesem algumas interpretações dicotômicas sobre a obra Entre o passado e o futuro, de Arendt (2013), segundo as quais a autora proporia um divórcio entre o "domínio da educação e os domínios da vida pública e política", encobrindo supostamente a dimensão política da educação e conservando as formas materiais e simbólicas de dominação, afirmamos que essa relação é inexorável na referida obra. Concordamos com Carvalho (2014), para quem o esforço analítico da autora foi ressaltar as diferenças entre esferas como uma condição inicial para uma melhor compreensão das relações intrínsecas entre elas. Certamente essa ausência de uma reflexão coletiva e democrática sobre a educação tem favorecido a ascensão do revisionismo histórico que nega o passado de desigualdades e permite a defesa da meritocracia branca e heteronormativa, da perspectiva negacionista ancorada em fundamentalismos religiosos e criacionistas, que despreza as concepções científicas, refutando, entre outras coisas, a gravidade da epidemia (segundo o atual presidente, seria apenas "gripezinha") regimes autoritários e as desigualdades impingidas aos grupos historicamente marginalizados.

Há que se destacar ainda que uma das estratégias do estado de exceção, principalmente no período da pandemia, tem sido controlar o fluxo das informações (AGAMBEN, 2020), como já ocorreu no período da ditadura, ocultando ou mesmo dificultando o acesso a dados e, por vezes, produzindo versões fantasiosas que visam confundir deliberadamente a população (enquanto escrevemos este artigo, desdobram-se as polêmicas em torno da não divulgação, por parte do Ministério da Saúde, dos números oficiais de infecção e óbitos relacionados à covid) ${ }^{\mathrm{vii}}$. Assim, lança-se à opinião pública, circunscrita por vezes na bolha das redes sociais, um debate perigoso, em que fake news são produzidas em escala industrial e disseminadas em escala global, alimentando as posições sectárias, o ódio contra "os outros" e impedindo que as relações de empatia e alteridade se estabeleçam entre os sujeitos contemporâneos. O negacionismo climático $^{\text {viii }}$, o desprezo pelas desigualdades históricas e a pouca preocupação com a distribuição de renda e com o acesso à educação para grupos desfavorecidos em função dos marcadores sociais de diferença têm sido traços comuns da atual política levada a cabo no Brasil. Compreendemos que a educação tem uma dimensão pública e política fundamental e, portanto, para além da dimensão 
formativa de transmissão dos conhecimentos historicamente apropriados pela humanidade, deve propiciar também uma leitura crítica do mundo. A universalização do acesso e o direito à informação e compreensão dos projetos de nação implícitos ou explícitos nas políticas estatais são fundamentais para uma educação cidadã não só dos estudantes, mas da sociedade como um todo, sobretudo em períodos em que emergências sanitárias são usadas para instaurar regimes de exceção. É, portanto, sobre o impacto da pandemia na educação pública e suas múltiplas relações com o campo sócio-político que nos debruçaremos a seguir. Para fins de organização, o ensaio está divido em duas partes. Na primeira, analisamos a dimensão política e social da pandemia e suas implicações para a educação e a democracia a partir da noção de "efeito colateral". Na segunda, a partir dos marcadores classe, gênero e raça/etnia, buscamos problematizar o caráter seletivo quem tem marcado algumas das políticas de combate à doença. Esperamos, a partir da articulação de tais elementos, evidenciar que no Brasil, mais do que uma questão meramente epidemiológica, ela é principalmente política.

\section{Pensando o corona e seus "efeitos colaterais" para a educação e a democracia brasileira}

Aqui fazemos deliberadamente o uso da categoria "efeito colateral", amplamente utilizada pelo aparato biomédico, a fim de problematizar as ressonâncias político-sociais da pandemia no Brasil e seus reflexos na (re)produção de desigualdades. Como dissemos anteriormente, o fenômeno não se esgota na área epidemiológica ou mesmo nos ambientes de laboratório (MOL, 2008; LATOUR e WOOLGAR, 1997). Ao contrário, trata-se de um campo cuja dimensão política é tão proeminente quanto o debate biomédico, com o agravante de que sobre ela incidem saberes-poderes, privilégios, prioridades, destino de financiamentos, disputas para uso/aplicação de verbas/recursos (bi)milionários etc. e que criam condições objetivas de decidir quais vidas são "dignas" e quais não são (BUTLER, 2015). Atentos a essa captura da pandemia pelo Estado e pela elite brasileira para impulsionar seu projeto biopolítico, no qual negros e pobres formam o grupo preferencial de vítimas, nos propusemos a investigar, brevemente, seus efeitos e repercussões, a fim de especular possíveis estratégias de enfrentamento das narrativas de normalização da morte negra e periférica como acontecimento inevitável.

A manifestação da covid-19 no final de 2019 na cidade de Wuham, na China, e sua posterior proliferação em escala global ao longo dos primeiros meses de 2020, nos confrontaram com uma série de contradições existentes em nosso modo de ser comunidade humana (AGAMBEN, 2020; SANTOS, 2020). A maior delas põe em confronto o sentido de comunidade e o funcionamento do mercado - este último narrando-se publicamente como a própria condição da existência do comum, ou seja, sem mercado não há emprego, renda, trabalho e chegaremos ao colapso; por outro lado, a comunidade é pensada como um valor a priori, no qual a vida é o valor fundamental e deve ser preservada a partir da intervenção do Estado no controle da pandemia. Nesse cenário, países caracterizados por uma elevadíssima desigualdade 
social e parco investimento em ciência e saúde pública, como o Brasil, expõem as fraturas de sua democracia, pois o acesso às políticas de proteção da vida, os efeitos no campo educacional e os desdobramentos da crise econômica atingem quase exclusivamente, mais uma vez, os negros e pobres. Numa sociedade marcada pelo sistema neoliberal, que num primeiro momento valorizou e estimulou o individualismo e a defesa de um Estado mínimo, e que agora propõe sua completa eliminação, reposicionando a dimensão individual - já que alguns indivíduos abrem mão do "cuidado de si” em carreatas e manifestações em favor do "direito de morrer e deixar morrer" - , contrariando as balizas clássicas do liberalismo e da educação cidadã e provocando um aumento na escalada da desigualdade econômica tanto entre países quanto entre as camadas sociais em seu interior, os efeitos da pandemia se tornam ainda piores.

Se comparamos o número de mortos em decorrência da Covid-19 pertencentes às camadas desprivilegiadas com as mais abastadas do país, perceberemos a dimensão seletiva que atravessa os efeitos sociais do vírus. De acordo com pesquisa realizada pela PUC-Rio, "pretos e partos sem escolaridade morrem quatro vezes mais pelo novo coronavírus do que brancos com nível superior $(80,35 \% \text { contra } 19,65 \%)^{\text {,ix }}$.

O mesmo se pode dizer dos inúmeros sujeitos que perderam a vida nos estados de São Paulo, Rio de Janeiro, Ceará e Amazonas (lugares com os maiores índices de infecção e mortalidade) e que sequer são contados como vítimas em decorrência dos problemas de subnotificação ${ }^{\mathrm{x}}$. Há um esmaecimento da dor quando o que conhecemos são números, não os sujeitos que, com sua morte, somaram esses números.

Assim, tais "efeitos colaterais", produzidos no tempo e nos espaços em escala global, constituídos e atravessados por relações de saber-poder, instaurados em zonas abissais (SANTOS, 2020), não têm o mesmo efeito e nem alcançam a todos do mesmo modo. Se não há nenhuma certeza quanto ao futuro, o que temos visto e experimentado no presente é que a pandemia veio a desvelar a insustentabilidade de alguns de nossos "mitos" (lembramos que o Brasil vive desde as eleições de 2018 a exaltação de um falso mito sustentado por fake news) e de nossas presunções civilizatórias. Especificamente desde nosso lugar, Brasil, ousamos dizer que a primeira coisa a ruir é a ideia fartamente compartilhada pelas elites brasileiras e reafirmada pelo discurso oficial de que o país é, em sua gênese, harmonioso, inclusivo e sem preconceitos (SOUZA, 2018; SCHWARCZ, 2019).

Se a epidemia entrou no país a partir de classes abastadas (os primeiros casos são de pessoas que estiveram em viagem pela Europa), aos poucos ela se disseminou para outras camadas da população, menos favorecidas. Como diz o pesquisador Pinto: “A pandemia é uma doença de classe" (PINTO, $2020)^{\mathrm{xi}}$. Assim, se num primeiro momento ingenuamente acreditamos que a disseminação do vírus nessa escala atingiria a todos de modo "democrático", aos poucos percebemos que essa aparente "igualdade" na infecção teria dimensões nada igualitárias em seus efeitos ${ }^{\mathrm{xii}}$. 
Para pensar alguns desses efeitos, especificamente no âmbito da educação, escolhemos algumas estratégias sugeridas pelo Ministério da Educação e adotadas por administrações de universidades brasileiras e institutos federais (IFs). De antemão, destacamos a responsabilidade do Estado, o qual tem a obrigação de promover uma educação crítica e, no caso em tela, de fornecer informações confiáveis sobre problemas de saúde, mas também ter transparência na gestão de recursos e tratamentos disponíveis, o que não vem ocorrendo em alguns países, como o Brasil. Esse processo tem se agravado com a constante militarização do Palácio do Planalto, em cargos que deveriam ser ocupados sob critérios técnicos, e não políticos, bem como as inúmeras tentativas de ocultamento de dados por parte da presidência da República no que diz respeito aos dados epidemiológicos ${ }^{\text {xiii }}$. Reafirmamos que cabe à educação, no caso da pandemia, além da informação, a análise crítica, de modo que as pessoas possam fazer cálculos de risco e adotar comportamentos adequados no seu enfrentamento e que sejam compatíveis com sua realidade socioeconômica e cultural com vistas ao bem viver. Com o vírus se espalhando rapidamente pelo mundo, vários países iniciaram diversas estratégias para impedir sua propagação, incluindo o fechamento de escolas. Além do Conselho Nacional de Educação, que publicou diretrizes para o funcionamento dessas instituições durante a pandemia, a Unesco, após a declaração, em 17 de maio, de que quase 1,21 bilhão os alunos foram afetados, representando $69,3 \%$ da população estudantil do mundo, organizou suas orientações para a educação por meio da publicação do Guidance on open educational

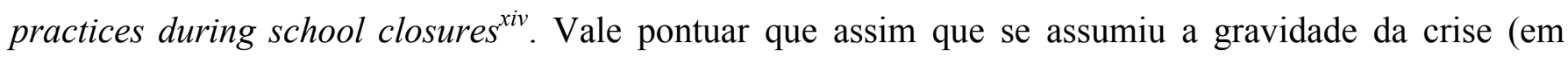
meados de março, com o aumento crescente e acelerado das infecções), muitas universidades do país tomaram como medida emergencial a suspensão das atividades presenciais, com a interrupção ou não do calendário acadêmico e a consequente adoção ou não de atividades remotas. Nos termos dessa estratégia estaria a defesa de seu caráter "seguro" (evitaria exposição e contato da comunidade acadêmica) e "democrático" (já que se pressupôs o acesso facilitado tanto à internet quanto às tecnologias digitais por parte de estudantes e professores $)^{\mathrm{xv}}$.

Tal pressuposto democrático não precisou de muito para ser confrontado com seu racismo estrutural (GONZALEZ, 2019). Se "um em cada 4 brasileiros não tem acesso à internet"xvi, outros milhares de brasileiros sequer têm o que comer. Como ignorar ainda que, antes da estratégia de suspensão das aulas, houve a recomendação, por parte de organismos internacionais, como a Organização Mundial da Saúde (OMS) e do Ministério da Saúde (MS), do uso indiscriminado de água e sabão? No entanto, estima-se que são mais de 18 milhões de pessoas e que 12\% dessa população, majoritariamente negra, sequer conta com sabão ou sabonete em casa ${ }^{\text {xvii }}$.

Assim, problemas que seriam apressadamente reduzidos a uma questão de ordem sanitária e/ou médica revelam estreitas conexões com outras, que não se esgotam no corpo, no sangue ou no vírus (MOL, 2008; LATOUR e WOOLGAR, 1997). Ao contrário, existe uma estreita relação entre saúde e 
determinantes sociais. Nesse sentido, não por acaso a pandemia no Brasil tem deixado suas marcas necropolíticas $^{\text {xviii }}$ majoritariamente entre pessoas atravessadas por marcadores como classe, raça/etnia, gênero e região.

A discussão sobre necropolítica de Mbembe (2016) volta-se principalmente à compreensão do Estado enquanto máquina de guerra e de como ele opera na produção de inimigos internos, contra os quais precisa agir. Nessa perspectiva criam-se as condições de possibilidade para decretar estados de exceção (como nos casos de guerra contra o terrorismo e contra o tráfico de drogas) e lançar mão da violência legítima, justificando a morte pela morte, em nome da soberania, tudo isso forjado em uma ordem discursiva pautada nos princípios clássicos do contrato social.

A necropolítica expande a noção de biopolítica de Foucault (1988): enquanto esta última se apoia no princípio de "fazer viver e deixar morrer", a primeira inverteria a proposição, amparando-se na premissa de "fazer morrer e deixar viver". Nessa perspectiva, a vida deixa de ser um projeto para ser uma concessão para aqueles que não representam perigo à soberania do Estado. A ideia de norma aqui é fundamental na definição de quem merece viver ou deve morrer, tendo em vista que aqueles atravessados pelos marcadores sociais da diferença são produzidos/tomados como ameaça, inimigos em potencial da norma e dos interesses hegemônicos. No caso da pandemia, biopolítica e necropolítica operam conjuntamente, deixando morrer (com subnotificações, omissão e negligência) e fazendo morrer (com decretos que colocam deliberadamente em risco a vida das pessoas, como a regulamentação de medicamentos sem eficácia comprovada e veto da obrigatoriedade do uso de máscaras nos presídios, só para citar alguns exemplos) aqueles que não se adequam a uma norma arbitrária e utilitária que define quem deve ser mantido vivo.

No caso das universidades, a adesão ao trabalho remoto também trouxe questões quanto à exposição e agravo das condições de vida e acesso daqueles que, pelos marcadores sociais da diferença, já partilham de uma "vida precária" (BUTLER, 2015). Especificamente considerando os contextos em que estamos inseridos, vale lembrar a presença de estudantes indígenas, quilombolas, assentados, de comunidades rurais e portadores de algum tipo de deficiência, dentre outros. Com relação a esse aspecto, no caso específico da UFGD, inicialmente por meio de uma portaria datada de 16 de março de $2020^{\mathrm{xix}}$, houve a recomendação de que, seguindo as orientações dos órgãos e instâncias de saúde pública, houvesse a interrupção das atividades presenciais, mas que os professores deveriam dar continuidade ao trabalho por meio da utilização de plataformas digitais. Dois dias depois (em 18 de março de 2020), após intensa mobilização por meio de notas de estudantes (via Diretório Central dos Estudantes-DCE) e de direções de faculdades que compõem a universidade, foi deliberada a suspensão do calendário acadêmico (o que permanece até o presente). Alguns pontos apresentados nessas notas ${ }^{\mathrm{xx}}$ merecem destaque e nos 
ajudarão a pensar os mecanismos perversos de exclusão que revestem as iniciativas de "combate" ao corona pelo país afora e que atingem de forma avassaladora a educação.

Dentre eles, destacam-se: a dificuldade de estudantes (a grande maioria) de acesso facilitado às redes sociais e às tecnologias de informação; a constatação de que em alguns casos (como de indígenas e assentados) sequer teriam acesso à energia elétrica em suas residências/comunidades; muitos residem em lugares remotos (p. ex. sítios e/ou municípios pequenos) e não podem contar com o fácil acesso a recursos e serviços de tecnologia digital; dada a especificidade de cada curso, há casos em que há o predomínio de atividades práticas que não podem ser realizadas de forma virtual; não habilitação ou dificuldade por parte de discentes e docentes na utilização de ferramentas digitais; muitos estudantes, por terem algum tipo de deficiência, não contam em suas residências com estrutura e apoio pedagógico adequado para a realização de atividades on-line; a preocupação, por parte acadêmicos e acadêmicas inseridos dentro do perfil de vulnerabilidade social, quanto à incerteza da manutenção de auxílios e benefícios, dentre outros. É nesse sentido que pontuamos que assumir o ensino à distância para uma instituição completamente voltada para a educação presencial exigiria um planejamento mínimo e uma estrutura emergencial que desse conta da contingência criada pela covid-19, sem que isso acarretasse algum nível de vulnerabilidade social, e muito menos exclusão de grupos e minorias (SEGATA, 2020; CASTORINO, 2020).

Dilemas semelhantes são compartilhados pelos institutos federais, que, de modo geral, estão localizados em regiões periféricas e cujo alunado pertence às camadas socialmente desprivilegiadas. Nesse sentido, essa preocupação é estendida, obviamente, ao funcionamento interno dos IFs, pois, uma vez que estão localizados em diversas regiões do território nacional e, em sua imensa maioria, longe dos grandes centros urbanos, recebem uma diversidade gigantesca de sujeitos e culturas que vivem em seu entorno, lidando tanto com o sujeito urbano, tecnológico e informatizado, quanto com o indivíduo que vive na zona rural $^{\mathrm{x} i}$, com acesso parcial ou nenhum acesso às tecnologias e mídias sociais. Junta-se a esse aspecto regional o ecossistema múltiplo que constitui a realidade de qualquer ambiente escolar público no Brasil: uma imensa disparidade de renda entre os estudantes, acesso desigual a bens e serviços e uma diversidade de sujeitos intensificada pela proximidade dessas instituições com as comunidades quilombolas, indígenas e ribeirinhas e com a zona rural, por exemplo. Nesse sentido, o espaço dos IFs se torna não apenas um lugar de encontro entre a comunidade escolar, mas também da comunidade escolar com uma série de bens, informações e acessos que são escassos em seus ambientes de moradia e suas comunidades.

Ademais, para além das vulnerabilidades sociais às quais milhares de estudantes estão submetidos no país, pouca atenção tem sido dada às condições de teletrabalho dos professores (SEGATA, 2020). Estes tiveram que, de uma hora para outra, organizar uma nova rotina de trabalho domiciliar, sem equipamentos e treinamento técnico adequados para o exercício de atividades à distância, para as quais 
não foram contratados e cuja realização só acontecia de modo esporádico. Nesse sentido, se os desafios do teletrabalho e da Educação à Distância (EAD) não surgiram com a pandemia, temos tido acesso a uma série de relatos por parte de colegas de universidades e IFs pelo país afora que narram sua complexificação. São inúmeras as narrativas de sensação de esgotamento face às contínuas demandas que o novo modelo de teletrabalho lhes impõe. Como desconsiderar que, além da alteração do modus operandi das atividades rotineiras (reuniões de curso, orientações de iniciação científica e pós-graduação, condução de pesquisas, produção acadêmica, relatórios etc.), agora também passam a atender turmas inteiras de diferentes disciplinas nessas plataformas que exigem participação e monitoramento contínuos?

Desafiam ainda a prática docente a readequação da linguagem, o volume de demandas virtuais e a exposição midiática, em que se espera dos professores e professoras a performance de youtubers e influenciadores das redes sociais, apresentando conteúdos criativos que sejam capazes de capturar a atenção dos estudantes em um contexto no qual outros estímulos da internet e da vida doméstica, além das ansiedades da vida pandêmica, colaboram para sua dispersão. Além disso, a noção de segurança em relação ao vírus, mobilizada pela estratégia de teletrabalho, não evidencia outras inseguranças às quais profissionais da educação estão expostos, como todo tipo de vulnerabilidade no que tange tanto à insegurança dos dados e monitoramento de conteúdos em tempos de patrulhamento ideológico, quanto às inseguranças trabalhistas, como a flexibilização e precarização do trabalho, suspensão de direitos, como auxílio transporte, adicionais (insalubridade, periculosidade, noturno etc.), comprometimento do gozo das férias e incertezas quanto à compensação das atividades realizadas durante a pandemia. Paralela à proposição de planos de trabalho referentes ao período da pandemia, o trabalho de planejamento para a retomada das atividades avoluma a quantidade de reuniões.

As dificuldades de profissionais de educação no que diz respeito aos desafios colocados pelo trabalho remoto também os afetam desigualmente, considerando a natureza do vínculo empregatício em instituições públicas ou privadas. A manutenção da continuidade de atividades virtuais na rede privada responde à lógica mercadológica, na qual os estudantes são clientes que estão pagando pela prestação de serviços educacionais e para os quais não pode haver ruptura do contrato, mesmo em tempos de pandemia, considerando, por exemplo, o cumprimento dos conteúdos, especialmente para os alunos que prestarão o Exame Nacional do Ensino Médio (Enem) em janeiro de 2021. Nas escolas e universidades públicas periféricas, a escassez de recursos tecnológicos e de acesso à internet é uma realidade que impede a manutenção das aulas e cuja continuidade implicaria no tratamento desigual dos estudantes.

As perspectivas pública e mercadológica da educação ficaram, portanto, radicalmente evidenciadas durante a pandemia, quando estudantes da rede privada continuam seguindo suas atividades, sem maiores discussões sobre a natureza e qualidade do trabalho a distância ou sobre as dificuldades, riscos e pressões aos quais docentes da rede privada estão submetidos, enquanto na rede pública tem 
havido um debate sobre as desigualdades e democratização do acesso à educação, bem como a reflexão e resistência acerca dos processos de sucateamento da educação presencial, além de iniciativas de educação continuada dos professores e professoras para trabalharem em plataformas de reuniões virtuais e educação a distância, com vistas à flexibilização/alternância entre as modalidades, mas com acompanhamento presencial, na medida em que não se sabe ao certo como será o cenário a partir da flexibilização do isolamento social. Como afirmou Thompson (2020), a "pandemia amplia abismo entre escolas públicas e privadas no Brasil"xxii.

A tentativa de antecipação dos possíveis cenários de retomada das atividades é outro tema que tem sido objeto de reflexões e angústias no campo da educação. Como adequar salas de aula que operam no limite de suas capacidades a novos protocolos de segurança? Como proteger professores e estudantes de novas infecções? Como estimar a reposição de conteúdos e cargas horárias em um cenário de incertezas? Se o contexto nos obriga a, em todos os domínios da vida, "viver um dia de cada vez", qualquer planejamento visando as saídas pós-pandêmicas para a educação esbarram em incertezas que dizem respeito não só à nossa segurança individual, mas também à segurança coletiva, além de precisar responder a demandas institucionais, burocráticas e políticas insensíveis à realidade das práticas educacionais cotidianas. Esse cenário de incertezas -- ao lado de pressões pela continuidade das atividades, ameaças de sucateamento das nossas condições de trabalho e da educação pública, bem como dos direitos trabalhistas, além de preocupações e cuidados para a manutenção da própria vida em meio a uma pandemia que, no país, chegou ao recorde diário cerca de mais de mil mortes (em 03 de junho deste ano, o país chegou a registrar o número de 1.349 mortes $)^{\text {xxiii }}$ - gera um estado generalizado de ansiedade e adoecimento mental em professoras e professores.

Nesse sentido, para nós, a dimensão pública da educação também se coloca como uma questão importante na compreensão dos impactos da pandemia. Não por acaso alguns autores têm chamado a atenção para a necessidade exercitarmos a "solidariedade genérica" (SAFATLE, 2020), ou seja, nos responsabilizarmos pela nossa vida e pela vida dos "outros". Essa dimensão passa necessariamente por pensar a dupla função do campo educacional, que deve, ao mesmo tempo, informar e formar a sociedade de forma crítica e, para isso, precisa a todo momento se confrontar com as informações que circulam no mundo social - função esta que passa a ser reconfigurada (e, num certo sentido, comprometida) no processo de virtualização da educação (CASTORINO, 2020). Nossa questão é: será que a produção de conteúdos continuará a ser pública e acessível para todos? Lembrando que a função do educador e do cidadão, de maneira geral na contemporaneidade, é a do provocador, que seleciona e problematiza o conglomerado informacional apresentando, debatendo, analisando e investigando o processo de circulação, difusão, recepção das narrativas nos diversos contextos sociais (SALIBA, 2015). Mas como 
pensar e aplicar isso num contexto como o que estamos vivendo e que altera de forma significativa não apenas os modos convencionais de interação, mas nossa própria subjetividade?

Nas sociedades democráticas todo cidadão e cidadã deve assumir sua responsabilidade no enfrentamento dos problemas em comum, selecionando, problematizando e checando a credibilidade das informações que circulam socialmente. Esse processo é fundamental para impedir a propagação de notícias falsas e o esgarçamento da opinião pública. Essa demanda acerca da interconexão entre informação e formação no atual contexto é condição sine qua non para o enfrentamento das práticas autoritárias que têm assumido lugares no (des)governo do Estado, inclusive no ocultamento e na censura das informações acerca da pandemia. Nesses termos, concordamos com Safatle que é preciso que retomemos a solidariedade como afeto político, que consiste em compreender que "minha vida depende de pessoas que eu nem sei quem são e que não parecem comigo, não fazem parte do meu grupo, mas que são fundamentais para a manutenção da outridade e do reconhecimento" (SAFATLE, 2020, s/p).

Mas como produzir esse reconhecimento do outro quando as estratégias de enfrentamento ganham contornos autoritários? Como ignorar o fato de o Ministério da Saúde passar a ser comandado, a partir de maio de 2020, pelo general Eduardo Pazuello - que sucedeu a dois ministros médicos que foram retirados do cargo por seguirem as recomendações da OMS e fornecerem regularmente informações à sociedade brasileira? A ascensão dos militares ao ministério levou a atenção à logística e ao mercado, mais do que ao combate à contaminação e à preservação da vida ${ }^{\text {xiv }}$. Vale lembrar que a omissão de informações sobre as vítimas da pandemia remonta e remete ao estado ditatorial estabelecido no Brasil entre 1964 e 1985 . É preciso que não se esqueça de que naquele período as informações - inclusive aquelas sobre os mortos pelo regime - foram também manipuladas e interditadas (ROSSI, 2019).

O poder de ditar quem deve viver e quem deve morrer evidencia um processo de desumanização da política moderna inerente ao sistema capitalista, tal com ele é proposto hoje. Esse modelo tem sido integralmente adotado pelo governo brasileiro no combate à pandemia, revelando como, para o Estado, certas vidas têm importado menos que o mercado. Por isso a política econômica é formulada a partir de um excedente não de mercadoria, nem de mão de obra, mas de mortos. Essa é a condição de possibilidade para o desenvolvimento econômico no período de crise pandêmica. Há que se lembrar, também, recorrendo à educação como elemento de suma importância na problematização da memória coletiva, que as táticas negacionistas utilizadas pelo governo já o foram em outros momentos da história brasileira, em que dados sobre as doenças eram ocultados de maneira deliberada, como forma de esconder da sociedade os seus nocivos efeitos e eliminar aqueles sujeitos que não estavam contemplados no projeto de desenvolvimento nacional, a exemplo dos indígenas e da parcela da população que muitas vezes morria e continua morrendo por falta de assistência médica, como ocorreu no caso da malária, da gripe espanhola, do sarampo e da meningite ${ }^{\mathrm{xxv}}$. 
Assim, tal constatação aponta para aquilo que Prado (2015), definiu como continuum da história brasileira: a despolitização do sofrimento e medicalização do mal-estar (cloroquina) e a “condominalização"xxvi dos sintomas. Na década de 1970, durante o recrudescimento da ditadura militar, houve um grande surto epidêmico de meningite, considerado um problema de segurança nacional que ameaçaria a falsa ideia de estabilidade econômica depositada no chamado milagre econômico (BARATA, 1988). Moraes e Barata (2005), em estudo sobre as características epidemiológicas da doença meningocócica na cidade de São Paulo durante o século XX, informam que os casos tiveram uma explosão no período de 1974 a 1975 e alcançaram a marca de 179,71 casos por mil habitantes. Ela se tornou um problema da esfera pública na medida em que passou a ser denominada como a epidemia da censura, conforme escreveu Clóvis Rossi (2019), jornalista e editor do Estadão no período de 1960 a 1970. Em artigo publicado à época, Rossi apontou que o problema sanitário tinha como ponto mais alto, a exemplo de agora, a epidemia da desinformação em todos os níveis promovida pelo Estado militar:

\begin{abstract}
Desde que, há dois anos aproximadamente, começaram a aumentar em ritmo alarmante os casos de meningite em São Paulo, as autoridades cuidaram de ocultar fatos, negar informações, reduzir os números referentes à doença a proporções incompatíveis com a realidade - ou seja, levando, deliberadamente, a desinformação à população e abrindo caminho para que boatos ocupassem rapidamente o lugar que deveria ser preenchido por fatos. Fatos que as autoridades tinham a obrigação, por todos os títulos de esclarecer ampla e totalmente. (...) Hoje, o que se pode ter é apenas um lado da verdade: o lado oficial, asséptico, geralmente otimista, ufanista o mais das vezes. Quem não aceita só esse lado, que leia poesias (ROSSI, 2019, s/p) $)^{\text {xxvii }}$.
\end{abstract}

Portanto, o que Rossi nos diz revela grande semelhança com o momento atual, pois naquele período os governos militares também procuraram perseguir a imprensa e seu direito de informar a população e ainda buscavam propagar diversas informações sobre obras faraônicas de infraestrutura, nem sempre finalizadas, com vistas a distrair a opinião pública e não responder a perguntas diretas, tais como: Quanto custaram as obras? Quantos mortos? Qual o planejamento do governo?

Desta feita, o atual (des)governo brasileiro dá continuidade à situação descrita por Rosalinda Santa Cruz no filme Que bom te ver viva (dir. Lúcia Murat, 1989), no qual afirma que a invenção mais cruel da ditadura é a figura do desaparecido, a crueldade expressa na suspensão do luto. O luto também foi, por vezes, atravessado pela mentira, quando assassinados pela ditadura tiveram impingida a si a marca do suicídio ou do acidente. A culpa, assim, seria daqueles que pereceram. Não seria também a lógica que atravessa o descaso do presidente Jair Bolsonaro em relação aos milhares de mortos vitimados pela covid e pela negação de que se trata de uma situação realmente grave?

O que dizer sobre essa cínica banalização das mortes? Como outrora, mais uma vez, socialmente e na intimidade familiar, o luto não pode ser vivido. Está interditado pela natureza da epidemia, assim como 
pela indiferença do Estado brasileiro. Diante desse cenário nos diz o presidente, em tom de deboche: "E daí?". A exemplo da ocultação de dados e mortes na ditadura militar, manipulam-se dados e minimizamse os impactos da pandemia. O luto, individual e coletivo, está atravessado pela política de naturalização da violência e de banalização da morte empreendida pelo atual (des)governo (MACIEL, 2020). Como aponta Rodrigues:

As falas e a atitudes do governo brasileiro, na figura do Presidente, não é tratar a morte como "condição inerente ao ser vivo, sendo esta a única certeza que se tem do desdobramento da existência humana" (ARAÚJO; VIEIRA, 2004, p. 361), é, sobretudo, a naturalização da morte (a "morte aceitável"), ou, a produção da morte (RODRIGUES, 2020, p. 19).

Cumpre ressaltar que ela não é uma invenção atual, tendo lastro temporal que remonta à imposição violenta da morte e às chacinas coloniais, mas agora se ratifica enquanto plataforma de governo, com vistas à manutenção pura do poder nas mãos de "quem sabe atirar" - lembrando que uma das imagens emblemáticas do atual governo são as inúmeras poses feitas pelo presidente e seus filhos e que remetem ao porte de armas.

Assim, podemos afirmar que há uma pedagogia genocida instalada estruturalmente no país direcionada a qualquer pessoa que conteste as atitudes do governo. É contra ela que outra educação precisa ser articulada. Essa política retoma a indiferença estratégica enquanto afeto político que faz com que o Estado negue e oculte dados e corpos como prática de continuidade autoritária e política oficial de extermínio (SAFATLE, 2020).

A indiferença estratégica em relação aos grupos socialmente marginalizados enquanto política de Estado em um governo que pensa em destruir o próprio Estado para a manutenção do poder fascista em sua pura e simples paixão pelo poder político e econômico investe naquilo que Moraes (2020) chamou de necrofilia colonialista outrocida, caracterizada por uma indisfarçável simpatia pela morte de negros, indígenas, mulheres, pobres, LGBTQI+ e idosos, operacionalizada nas escolhas das políticas de distribuição de renda ou mesmo dos pacientes que terão direito à vida nos leitos. Assim, o Estado e aqueles que estão no poder se tornam porta-vozes do colonizador e sua histórica empreitada genocida, fazendo com que os laços de solidariedade sejam esvaídos pela naturalização da violência e a indiferença deliberada pelo outro, fazendo com que o modo de lidar com a pandemia se torne a face escrachada do projeto necropolítico consolidado nas eleições de 2018 (MBEMBE, 2016). Portanto, não é mera coincidência a inserção de militares no aparelhamento do Estado - por meio dela, abre-se espaço na sociedade brasileira para reavivar o ressentimento, um projeto interrompido de autoritarismo e violência que remonta a décadas atrás (sem reparação jurídica e histórica). 
Outrossim, Santos (2020) analisa a ascensão da extrema-direita em nível global e sua pulsão de "antissistema" que ataca as instituições democráticas consolidadas, flerta com o fascismo e ataca a ciência, a educação pública e a liberdade de imprensa das mídias convencionais, deslocando os debates políticos para a esfera das redes sociais, em que a produção e/ou distorção de informações é financiada por conglomerados empresariais que manipulam a opinião pública, criando a falsa ideia de que seu pensamento reflete a visão de toda a sociedade, como ocorre no Brasil.

Outro traço destacado por Santos (2020) é o fato de essa direita hiperliberal e fascista (ou, como eles mesmos têm se autodenominado, "liberais conservadores"), de um lado defender políticas extremamente austeras para a população em geral e, de outro, priorizar as verbas para militares e forças de segurança, com o objetivo de apoio das forças repressivas em caso de processos de ruptura da ordem democrática. No caso do Brasil, os argumentos "estamos em tempos de crise" ou "precisamos de medidas de austeridade" têm servido para justificar os ataques ao funcionalismo público e à precarização dos direitos trabalhistas. Nesse sentido, a economia tem sido a justificativa para que governos descumpram as medidas de distanciamento social e menosprezem os efeitos letais do vírus.

Deram a entender que uma dose de darwinismo social seria benéfica: a eliminação de parte das populações que já não interessam à economia, nem como trabalhadores nem como consumidores, ou seja, populações descartáveis como se a economia pudesse prosperar sobre uma pilha de cadáveres ou de corpos desprovidos de qualquer rendimento. Os exemplos mais marcantes são a Inglaterra, os EUA, o Brasil, a Índia, as Filipinas e a Tailândia (SANTOS, 2020, p. 26).

Numa completa inversão de papéis, as informações que deveriam ser fornecidas pelo Estado e pelos seus ministérios passam a ser dadas pela grande imprensa, cujo capital político e econômico é inegavelmente vinculado às elites brasileiras e cujos interesses não são necessariamente o do bem comum. Nesse cenário obscurantista, qual o lugar que se dará (que é dado) à educação?

\section{Falar de corona é falar sobre marcadores sociais de diferença}

As questões que trouxemos acima, seus dilemas e complexidades para a educação e a democracia, apontam para o caráter "tentacular" dos efeitos da pandemia. Nesse sentido, acreditamos que, embora seja possível fazer um recorte no que tange aos reflexos da crise no campo da educação e da democracia, o debate não se encerra nessa seara. Antes, é fundamental um olhar atento às mazelas estruturais que constituem a sociedade brasileira e que, sustentadas no racismo, no sexismo e nos privilégios de classe, nos permitem compreender o caráter seletivo dos efeitos colaterais da pandemia.

Acreditamos que a perspectiva interseccional, ou dos marcadores sociais de diferença, tem muito a contribuir. Assim, não podemos ignorar a importância da mobilização realizada por mulheres negras em 
finais do século XIX e pelo movimento lésbico da década de 70 do século XX para os desdobramentos teórico-analíticos em torno das interseccionalidades (HENNING, 2015). Além disso, o trabalho de teóricas feministas em fins da década de 1980 e início da década de 1990 também é fundamental para a consolidação de uma perspectiva que compreende os mecanismos de opressão de forma articulada (PISCITELLI, 2008). Isso resulta em que, no interior do debate, não seja possível afirmar a existência uma perspectiva única e/ou homogênea (NASH, 2008).

Kimberlé Crenshaw é apontada como a primeira a utilizar a categoria interssecionalidade (HENNING, 2015). Contudo, outras intelectuais negras, como Angela Davis (2016 [1981]) e bell hooks (1982), já no início da década de 1980, ao questionarem o movimento feminista hegemônico (branco, classe média, letrado), apontavam para a necessidade de articulação entre as discussões de gênero, classe e raça. Em ambas as autoras há clareza quanto ao fato de que as opressões não atingem a todos da mesma maneira.

Crenshaw (2012 [1991]), por sua vez, a partir de suas pesquisas junto a afroamericanas, latinas e imigrantes em situação de violência e vulnerabilidade social, constata como raça, gênero e classe estão estreitamente inter-relacionados e são convergentes. Nesse sentido, a autora problematiza como "las experiencias de las mujeres de color evidencian como intersectan las diferentes estructuras, donde la dimensión de clase no es independiente de la de raza o género" (2012, p. 91).

No caso do Brasil, como dissemos anteriormente, não por acaso os dados da pandemia passam a revelar que os mais atingidos ou mais vulneráveis se encontram atravessados pelos marcadores de classe (mais pobres), raça/etnia (negros e indígenas), gênero (principalmente mulheres) e região (principalmente periferias de grandes cidades, ainda mais aquelas localizadas fora do eixo sul-sudeste ).

Se as desigualdades atualmente vistas em nosso país em torno da covid não são uma novidade, elas se agravam quando consideramos tais marcadores. Nesse sentido, como pontuado anteriormente, é importante dizer que a desigualdade não se inicia com a covid-19. A grande "novidade" é que agora autoridades estatais assumem a morte como um projeto político-econômico declarado. Ou seja, não é possível ignorarmos que, desde o início de nossa história, a sociedade brasileira tem se constituído como um campo fértil de produção de assimetrias (sustentadas em violência, racismo, sexismo e classismo) que têm sido mascaradas pelo discurso culturalista de "cordialidade" e "miscigenação" (SOUZA, 2018; SCHWARCZ, 2019) ${ }^{\mathrm{xxviii}}$, fortemente desconstruído agora, com a crise escancarada pela doença.

Portanto, sujeitos e coletivos historicamente invisibilizados pela sociedade brasileira (geralmente atravessados pelos marcadores de classe, raça e gênero) passam a ocupar a linha de frente nas políticas de morte (MBEMBE, 2016). A face perversa é que, se no cotidiano essa população sofre rotineiramente com os serviços públicos precarizados (saneamento básico, transporte, saúde, educação), em tempos de crise 
essa negação, que é banalizada, tende a ganhar as páginas dos noticiários e dos discursos políticos como novidade (OLIVEIRA, SATHLER, LOPES, 2020).

Nesse sentido, têm sido evidentes os impactos da pandemia na produção e no agravamento das desigualdades de gênero. Para Castro e Chagury (2020), o marcador gênero tem se colocado como um aspecto bastante importante na produção de assimetrias entre homens e mulheres em tempos de covid-19. Com relação a isso, as pesquisadoras apontam que a quantidade de trabalhos acadêmicos publicados por mulheres durante esse período teve queda significativa em relação aos homens. Esse fato não parece estranhar à medida que consideramos que, nessa nova reconfiguração, as mulheres têm assumido a linha de frente no cuidado dos afazeres domésticos e de seus familiares. O patriarcado e o sexismo delegam à mulher o papel de "cuidadoras do mundo", cuja função seria cuidar de todos, fora e dentro de casa, assumindo empregos como enfermagem ou assistência social, abrindo mão de cumprirem seu isolamento social em favor da vida de "outros", exercitando sua "solidariedade genérica" (SANTOS, 2020).

Nesse quesito, muitos professores e professoras se queixam do aumento da demanda de trabalho virtual que, junto com os afazeres domésticos, as demandas exaustivas de limpeza colocadas pela necessidade de prevenção e o cuidado com os filhos, resultam em um nível acentuado de estresse, principalmente no que tange às professoras. Há que se lembrar ainda que $45 \%$ dos lares brasileiros são chefiados por mulheres que ganham 20,5\% menos que os homens para desempenharem as mesmas funções; muitas dessas mulheres são mães solo e têm que sustentar seus filhos sozinhas, tornando-se alvos fáceis da infecção ao ficarem mais expostas pela necessidade de sobrevivência (BRASIL ECONÔMICO, 2020) $)^{\text {xxix }}$.

Nessa perspectiva, os efeitos dessa experiência, conforme evidencia a Organização ONU Mulheres $(2020)^{\mathrm{xxx}}$, será sentido de modo mais grave entre as mulheres, sobre as quais ainda recai de modo predominante o trabalho doméstico. Assim, o marcador gênero também se mostra importante na análise sobre os impactos da pandemia na medida em que são também mulheres a maioria das profissionais que atuam na linha de frente no enfrentamento da covid-19, principalmente na área da saúde.

Outro marcador é a raça/etnia. Em se tratando especificamente do contexto atual, pesquisadores, pesquisadoras e organizações não-governamentais têm questionado os limites e vieses das estatísticas. Vale lembrar que logo no início da pandemia no Brasil dizia-se que o maior número de infectados era de pessoas brancas. Mas, ao contrário, como questionaram na época pesquisadores, pesquisadoras e lideranças do movimento negro, não é possível que os dados sejam fidedignos, à medida que se constata que o acesso aos testes era mais facilitado às camadas médias e altas (onde se localiza majoritariamente a população branca). Assim, não por acaso, o "[...] número de negros mortos por coronavírus é cinco vezes maior no Brasil" (MUNIZ, FONSECA, PINA, 2020, s/p) ${ }^{\mathrm{xxxi}}$. 
Ou seja, há um alto índice de subnotificação que está estreitamente relacionado ao fato de ter ou não acesso, o que é marcado pela raça e pela classe. Santos (2020) revela uma pedagogia cruel do vírus que, ao operar a partir dos marcadores da diferença, traz maior sofrimento para mulheres, negros, trabalhadores e a população de rua, alvos preferenciais da necropolítica econômica e do sistema de saúde. Concordamos com o autor quando afirma que

As pandemias não matam tão indiscriminadamente quanto se julga. É evidente que são menos discriminatórias que outras violências cometidas na nossa sociedade contra trabalhadores empobrecidos, mulheres, trabalhadores precários, negros, indígenas, imigrantes, refugiados, sem abrigo, camponeses, idosos, etc. (SANTOS, 2020, p. 23).

Por aqui temos uma máquina de guerra necropolítica voltada contra corpos pobres e pretos que, sem a possibilidade de manter o distanciamento social por viverem em cubículos improvisados e amontoados em condições subumanas nas favelas, morros e periferias ${ }^{\text {xxxii }}$, tornam-se ainda mais vulneráveis aos efeitos nefastos da pandemia.

Finalmente, há que se lembrar a questão dos povos indígenas, que, em função de suas marcas étnicas, sofreram (e ainda sofrem) ataques desde a invasão dos colonizadores brancos, em 1500, e tiveram suas terras espoliadas, foram expulsos das mesmas e dizimados pelas doenças levadas pelos brancos, principalmente nos projetos desenvolvimentistas do período do Estado ditatorial que perdurou no país de 1964 a 1985. Agora o sofrimento vem, como no passado, em forma de vírus e do desamparo, já que muitos desses indígenas têm dificuldades em acessar o auxílio emergencial para se sustentarem novamente são as mulheres indígenas que se deslocam para as cidades, como Aquidauana-MS, para vender seus produtos e ganhar o sustento ${ }^{\text {xxxiii }}$.

No caso da reserva indígena de Dourados, segundo o último boletim epidemiológico divulgado (DSEI-MS/SESAI, 2020) ${ }^{\text {xxxiv }}$, até o momento tiveram confirmação para Covid-19 88 indígenas GuaraniKaiowá (o que, segundo a mesma fonte, representa 87\% dos casos envolvendo indígenas no Estado). O número bruto não dá conta de expressar as inúmeras vulnerabilidades sociais a que são submetidos cotidianamente Guaranis, Kaiowás e Terenas no sul do Mato Grosso do Sul e cujo o impacto das infecções por corona tende a ser avassalador (como desconsiderar, por exemplo, que vivem confinados nas reservas em condições precárias de saúde e saneamento básico, seja pela inércia, seja pela omissão do Estado?). Segundo algumas lideranças, a atualização dos dados tem sido bastante dificultada pela demora na liberação dos resultados dos exames.

No caso da região nordeste, destacamos os dados referentes ao estado da Bahia, ao qual pertencem dois dos autores: 
O número de casos tem crescido assustadoramente em cidades da região extremo-sul da Bahia. A Secretaria Municipal de Porto Seguro, por exemplo, registrou no dia de ontem [04/06/2020] 172 casos confirmados e outros 78 aguardando resultado de exames. Em Itamaraju, são 187 casos confirmados e 2 aguardando resultado. Já em Eunápolis, 203 casos confirmados e outros 170 em vias de confirmação. Esse contexto tem despertado muita preocupação entre o povo Pataxó. Finalmente, no boletim desta semana, publicamos o mapa "Indígenas Contra a COVID na Bahia". Nele, além de apresentarmos os números relativos à doença, indicamos a localização das 68 Terras e ocupações indígenas e das 26 etnias indígenas no estado, destacando que, daquelas Terras e ocupações, apenas 26 tem iniciado algum processo de regularização fundiária, seguindo as demais sem nenhuma iniciativa de regularização, o que só indica, de modo eloquente, a sua vulnerabilidade (MUPOÍBA, 2020) xxv $^{\mathrm{xxv}}$

Além disso, há dificuldades para contar seus mortos ${ }^{\text {xxxvi }}$, pois o ocultamento e/ou manipulação dos números impede que haja um acompanhamento real das mortes, somado ao fato de que, dada a gravidade da pandemia, sequer podem realizar seus ritos fúnebres, ocasionando também desordens tanto na dimensão comunitária quanto cosmológica desses grupos. As próprias organizações indígenas apresentam divergência entre os números: encontramos na Secretaria Especial de Saúde Indígena (SESAI) o registro de 70 mortes, enquanto a Articulação dos Povos Indígenas do Brasil (APIB) indica 221 (CIMI, 2020) ${ }^{\mathrm{xxxvii}}$, demonstrando a falta de uma política de informação por parte do Ministério da Saúde. A partir desses exemplos aludidos, percebemos que a pandemia tem servido para chancelar estados contínuos de exceção a fim de torná-los regras de extermínios de corpos etnicorracializados. Em relação a isso, Becker, Oliveira e Martins (2016) mencionam como não é possível desvincular a existência, a intensidade e a recorrência da(s) violência(s) contra minorias existentes no estado de Mato Grosso do Sul de uma ideologia sexista, racista e patriarcal. Como apontam as pesquisadoras e o pesquisador:

Em solo sul mato-grossense esse é um dos indicadores da intolerância e do ódio que verte seu sangue, tal como se marca a ferro e a fogo o gado, mas, é claro sem que esses objetos corporificados e generificados no feminino, como travestis, gays, transexuais, mulheres [e indígenas] tenham o valor que o gado assume por aqui (BECKER; OLIVEIRA; MARTINS, 2016, s/p) $)^{\mathrm{xxxviii}}$.

\section{Algumas (in)conclusões finais}

As especificidades com as quais as experiências da pandemia se manifestam evidenciam as controvérsias da noção de democracia sobre a qual se assenta a organização da sociedade brasileira, bem como os dilemas que cercam o campo da educação. Na contramão dos discursos acerca da excepcionalidade da qual se reveste a expansão do coronavírus no Brasil, buscamos evidenciar que problemas crônicos, como racismo, sexismo e classicismo expõem desigualmente nossa população aos efeitos da covid-19 e à morte. Nesse sentido, longe de trazer novos problemas, ela coloca holofotes sobre questões que nunca resolvemos de fato. Isto é, as noções de excepcionalismo e crise não servem a uma 
analítica da pandemia, já que o que ela faz é expor e atualizar as normas de funcionamento da sociedade brasileira e ao velho projeto de Estado, historicamente violento e autoritário. Mesmo do ponto de vista da saúde, o caráter excepcional da crise é subvertido em análises que estabelecem aproximações com outras infecções virais e epidemias da nossa história, como a febre amarela, a varíola, a gripe espanhola e o HIV-aids.

É importante pontuar também que a covid-19 tem posto as sociedades diante de um dilema ético caro ao nosso tempo, uma encruzilhada entre a vida e o mercado. E nem sempre os governos têm escolhido a vida, o cuidado, e a saúde. Ao contrário, o que tem sido amplamente difundido é o "direito" de sacrificar a vida de inúmeras pessoas em nome de "salvar" a economia. O resultado dessa escolha terá reflexos em nosso combalido senso de comunidade, e cujas lições deixaremos para as gerações futuras. Questões que não se esgotam, como gostariam alguns, ao campo biomédico.

Ao nos voltarmos para as complexidades e contradições que cercam a opção pelo ensino EaD, também quisemos problematizar os dilemas que cercam a educação e a democracia contemporânea no Brasil. Ao recuarmos em alguns eventos da história recente do país, quisemos marcar que a violência e o autoritarismo não são novidade. Antes, são aspectos estruturalmente constituintes de nossa identidade, assim como o racismo. Não por acaso vemos a defesa ferrenha da continuidade das atividades acadêmicas por amplos setores da sociedade brasileira, ainda que na prática isso signifique o sucesso e não exposição de poucos em detrimentos de muitos. Trazer essa pauta implica, portanto, pensar em condições, acessos e direitos. Como consequência, também demandaria de nós uma revisão de nossos valores, pressupostos e privilégios. Disso depende um futuro no qual o senso de pertencimento coletivo se materialize efetivamente de forma mais democrática, humana e solidária. $\mathrm{O}$ " $\mathrm{x}$ " da questão é se há disposição coletiva para tal.

Por fim, esperamos ter deixado claro que, se não há possibilidade de nenhuma previsão quanto ao futuro que nos espera, cada vez mais incerto (quanto aos impactos na economia, na educação, relações, subjetividades e na própria democracia), problematizar as artimanhas necropolíticas do tempo presente, cuja legitimidade tem sido sustentada pelo discurso de "emergência", "crise", "calamidade", e enfrentada sem pudor e constrangimento com obscurantismo, violência e autoritarismo, seja o grande desafio da educação, das ciências humanas e sociais, cuja responsabilidade ético-política carregam. Talvez assim compreendamos as inúmeras acusações, perseguições, deslegitimações a que universidades, institutos de pesquisa, pesquisadores, pesquisadoras, professores e professoras têm sido constantemente submetidos no Brasil atual.

\section{Referências:}


AGAMBEN, G. Reflexões sobre a peste: Ensaios em tempos de pandemia. São Paulo: Boitempo, 2020.

ARENDT, H. Entre o passado e o futuro. São Paulo: Perspectiva, 2013

BARATA, R. Meningite: uma doença sob censura? São Paulo: Editora Cortez; 1988.

BECKER, S; OLIVEIRA, E. A.; MARTINS, C. P.. Onde fala a bala, cala a fala. Rede Humaniza SUS, 19 jun, 2016. Disponível em: <http://redehumanizasus.net/94812-onde-fala-a-bala-cala-a-fala $>$. Acesso em: 08 jun. 2020.

BUTLER, J. Quadros de guerra: quando a vida é passível de luto? Rio de Janeiro: Civilização Brasileira, 2015.

CARVAlHO, J. S. F. Política e educação em Hannah Arendt: distinções, relações e tensões. Educ. Soc. [online], 2014.

CASTORINO, A. Ensino à distância como armadilha perfeita. Cadernos Textos e Debates - Núcleo de Estudos de Identidade e Relações Interétnicas, Florianópolis/UFSC, n. 20, 2020.

CASTRO, B.; CHAGURI, M.. Um tempo só para si: gênero, pandemia e uma política científica feminista. ABET - Associação brasileira de estudos do trabalho, 2020. Disponível em: <http://abettrabalho.org.br/um-tempo-so-para-si-genero-pandemia-e-uma-politica-cientifica-feminista/>. Acesso: 05 jun. 2020.

CRENSHAW, K. Cartografiando los márgenes. Interseccionalidad, políticas identitarias, y violencia contra las mujeres de color. In: PLATERO, R. L. (Ed.). Intersecciones: cuerpos y sexualidades en la encrucijada. Temas contemporáneos. Barcelona: Bellaterra, 2012 [1991]. p. 87-122.

DAVIS, A. Mulheres, raça e classe. São Paulo: Boitempo Editorial, 2016 [1981].

FOUCAULT, M. História da Sexualidade: A vontade de saber. Vol I. Rio de Janeiro: Edições Graal, 1988.

GASTALDI, F. C. Gramsci e o negacionismo climático estadunidense: a construção do discurso hegemônico no Antropoceno. Revista Neiba, Cadernos Argentina Brasil, v. 7, n. 1, 2018.

GONZALEZ, L. A categoria político-cultural de Amefricanidade. In: HOLLANDA, H. B. H. (Org.). Pensamento feminista: conceitos fundamentais. Rio de Janeiro: Bazar do Tempo, 2019. p. 341-352.

HENNING, C. E. Interseccionalidade e pensamento feminista: As contribuições históricas e os debates contemporâneos acerca do entrelaçamento de marcadores sociais da diferença. Mediações, Londrina, v. 20 n. 2, p. 97-128, jul./dez. 2015.

HOOKS, b. Ain't I a Woman: Black Women and Feminism. London, Winchester: Pluto Press, 1982.

LATOUR, B.; WOOLGAR, S. A vida de laboratório: a produção dos fatos científicos. Rio de Janeiro: Relume Dumará, 1997.

MACIEL, W. C. Pandemia, necropolítica e purificação simbólica dos cuidadores da morte. Boletim Cientistas Sociais, Anpocs, n. 66. 
MORAES, J. C.; BARATA, R. B. A doença meningocócica em São Paulo, Brasil, no século XX: características epidemiológicas. Cad. Saúde Pública [online]. 2005, vol. 21, n. 5.

MORAES, W. A necrofilía colonialista outrocída no Brasil. Revista Estudos Libertários, v. 2, n. 3, 2020.

MBEMBE, A. Necropolítica. Arte \& Ensaios, Rio de Janeiro, n. 32, v. 2, 2016, p. 122-151.

MOL, A. Política ontológica. Algumas ideias e várias perguntas. In: NUNES, J. A.; ROQUE, R. (Org.). Objectos impuros: experiências em estudos sobre a ciência. Porto: Afrontamento, 2008. p. 63-75.

MUNIZ, B.; FONSECA, B.; PINA, R. Em duas semanas, número de negros mortos por coronavírus é cinco vezes maior no Brasil. Pública - Agência de Jornalismo Investigativo. 06 mai. 2020. Disponível em: $<$ https://apublica.org/2020/05/em-duas-semanas-numero-de-negros-mortos-por-coronavirus-e-cincovezes-maior-no-brasil/>. Acesso em: 09 jul. 2020.

NASH, J. C.. Re-thinking intersectionality. Feminist review, 89, p. 1-15, 2008.

OLIVEIRA, E. A.; SATHLER, C. N.; LOPES, R. C.. RAP como Educação para a Resistência e (Re)existência. Revista Eletrônica do Mestrado em Educação Ambiental, v. 37, p. 388-410, 2020.

PISCITELLI, A. Interseccionalidades, categorias de articulação e experiências de migrantes brasileiras. Sociedade e Cultura. v. 11, n. 2, p. 263-274, jul/dez. 2008.

PINTO, M. A. C. A pandemia é uma doença de classe: a catástrofe brasileira ainda está por vir. Carta capital online, 11 abr. 2020. Disponível em: <https://www.cartacapital.com.br/blogs/brasil-debate/apandemia-e-uma-doenca-de-classe-a-catastrofe-brasileira-ainda-esta-por-vir/>. Acesso em: 01 jun. 2020.

PRADO, J. L. A. Orelhas do livro. In: DUNKER, C. Mal-estar, sofrimento e sintoma. São Paulo: Boitempo, 2015.

QUE bom te ver viva. Direção de Lúcia Murat. Brasil: Taiga Produções Visuais, 1989 (97 min.).

RODRIGUES, J. Narrativas políticas, produção de vulnerabilidades e convulsão social no Brasil e no mundo, no contexto do Novo Coronavírus. Papers do NAEA, 29.1, 2020.

ROSSI, C. A epidemia do silêncio. Estadão, edição de 14 jun. 2019. Disponível em: $<$ http://m.acervo.estadao.com.br/noticias/acervo,a-epidemia-do-silencio-texto-censurado-de-clovis-rossiem-1974,70002872715,0.htm>. Acesso em 07 jun. 2020.

SCHWARCZ, L. M. Sobre o autoritarismo brasileiro. São Paulo: Companhia das letras, 2019.

SAFATLE, V. Bem vindo ao estado suicidário. Edições n-1, 2020. Disponível em: <https://n1edicoes.org/004>. Acesso em: 23 mai. 2020.

SALIBA, E. T. JORNADA O lugar da História no ensino escolar. Associação Nacional de História. São Paulo: ANPUH, 2015. 1 vídeo $(420 \mathrm{~min})$, online, son., color. Disponível em: $<$ https://www.youtube.com/watch?v=XB628GqcWTY> Acesso em: 20 jan. 2020.

SANTOS, B. S. A cruel pedagogia do vírus. Coimbra: Almedina, 2020. 
SCHNEIDER, C. M.; TAVARES, M.; MUSSE, C. O retrato da epidemia de meningite em 1971 e 1974 nos jornais O Globo e Folha de S. Paulo. Revista Eletrônica de Comunicação, Informação e Inovação em Saúde, v. 9, n. 4, 2015.

SEGATA, J. A colonização digital do isolamento. Cadernos de Campo, São Paulo, v. 29, n. 1, p. 163$171,2020$.

SOUZA, J (Org). A ralé brasileira: quem é e como vive. 3. ed. São Paulo: Editora Contracorrente, 2018.

THOMPSON, M. Pandemia amplia abismo entre escolas públicas e privadas no Brasil. Folha online, 30 mai. 2020. Disponível em: <https://www1.folha.uol.com.br/educacao/2020/05/pandemia-amplia-abismoentre-escolas-publicas-e-privadas-no-brasil.shtml>. Acesso em: 08 jul. 2020.

${ }^{i}$ Doutor em Antropologia Social (PPGAS/UFSC), Docente do Programa de Pós-Graduação em Antropologia da Universidade Federal da Grande Dourados (PPGAnt/UFGD) e do Programa de Pós-Graduação em Antropologia Social da Universidade Federal de Mato Grosso do Sul (PPGAS/UFMS). Dourados, MS, Brasil. Email: esmael oliveira@live.com Orcid: https://orcid.org/0000-0002-9235-5938

ii Doutor em Educação (UNICAMP), Docente do Programa de Pós-Graduação em Estudos Culturais da Universidade Federal de Mato Grosso do Sul. Campo Grande, MS, Brasil. Email: aguinaldorod@gmail.com Orcid: https://orcid.org/0000-00022398-8088

iii Mestra em Antropologia Social (PPGA/UFBA), Doutoranda no Programa de Pós-graduação em Antropologia Social da Universidade Federal do Rio Grande do Sul (PPGAS/UFRGS), Professora de Sociologia do Instituto Federal de Educação Ciência e Tecnologia da Bahia (IFBA). Salvador, BA, Brasil. Email: taty_rp@yahoo.com.br Orcid: https://orcid.org/00000003-1114-8978

${ }^{\text {iv }}$ Mestre em Estudos de Linguagem pela Universidade do Estado da Bahia (UNEB), Doutorando em Literatura e Crítica da Cultura pela Universidade Federal da Bahia (PPGLITCULT/UFBA), Professor do Instituto Federal de Educação, Ciência e Tecnologia Baiano (IFBaiano). Salvador, BA, Brasil. Email: jorgeaugustodamaia@gmail.com Orcid: http://orcid.org/00000002-6403-7860

"Compreendemos a categoria "efeitos colaterais" como os impactos sociais e políticos produzidos no Brasil em torno da pandemia de Covid-19. Tal discussão será melhor desenvolvida ao longo do ensaio.

${ }^{v i}$ Disponível em: https:/g1.globo.com/politica/blog/gerson-camarotti/post/2020/03/20/em-meio-a-pandemia-de-coronavirusbolsonaro-diz-que-gripezinha-nao-vai-derruba-lo.ghtml. Acesso em: 01 jun. 2020.

vii Disponível em: https://noticias.uol.com.br/ultimas-noticias/agencia-brasil/2020/06/08/ministerio-da-saude-muda-formatode-divulgacao-de-dados-de-covid-19.htm. Acesso em: 01 jun. 2020.

viii Concordando com Gastaldi, "negacionismo climático" é aqui empregado em seu sentido mais amplo, abrangendo as diversas formas de ceticismo relacionadas à veracidade do aquecimento global ou ao seu caráter antropogênico. Incluem-se também aqueles que, embora acreditem que o fenômeno seja real e influenciado pela ação humana, questionam a forma como é usualmente representado (creem, por exemplo, que os cientistas não-negacionistas exageram ao abordar o ritmo e a extensão dos impactos) (GASTALDI, 2018, p. 07).

${ }^{\text {ix }}$ Disponível em: https://revistagalileu.globo.com/Sociedade/noticia/2020/05/na-pandemia-de-covid-19-negros-morrem-maisdo-que-brancos-por-que.html. Acesso em: 01 jun. 2020.

x Disponível em: https://saude.abril.com.br/medicina/coronavirus-estimativa-aponta-numero-de-casos-14x-maior-do-que-ooficial/. Acesso em: 01 jun. 2020.

xi Disponível em: https://www.cartacapital.com.br/blogs/brasil-debate/a-pandemia-e-uma-doenca-de-classe-a-catastrofebrasileira-ainda-esta-por-vir/. Acesso em: 01 jun. 2020.

xii Disponível em: https://oglobo.globo.com/sociedade/covid-19-mais-letal-em-regioes-de-periferia-no-brasil-1-24407520. Acesso em 01 jun. 2020.

xiii Disponível em: https://noticias.uol.com.br/ultimas-noticias/agencia-brasil/2020/06/08/ministerio-da-saude-muda-formatode-divulgacao-de-dados-de-covid-19.htm. Acesso em: 01 jun. 2020.

xiv O documento está disponível em: https://iite.unesco.org/wp-content/uploads/2020/05/Guidance-on-Open-EducationalPractices-during-School-Closures-English-Version-V1 0.pdf. Acesso em: 09/07/2020.

${ }^{x v}$ No caso específico da UFGD isso foi expresso na resolução n. 106, de 29/06/2020, que preconiza a retomada das atividades acadêmicas de forma remota. 
${ }^{\text {xvi }}$ Disponível em: https://agenciabrasil.ebc.com.br/economia/noticia/2020-04/um-em-cada-quatro-brasileiros-nao-tem-acessointernet. Acesso em: 01 jun. 2020.

xvii Disponível em: https://g1.globo.com/economia/noticia/2020/05/06/cerca-de-184-milhoes-de-brasileiros-nao-recebem-aguaencanada-diariamente-aponta-ibge.ghtml. Acesso em: 01 jun. 2020.

xviii Achille Mbembe propõe "a noção de necropolítica e de necropoder para dar conta das várias maneiras pelas quais, em nosso mundo contemporâneo, as armas de fogo são dispostas com o objetivo de provocar a destruição máxima de pessoas e criar "mundos de morte", formas únicas e novas de existência social, nas quais vastas populações são submetidas a condições de vida que lhes conferem o estatuto de "mortos-vivos" (MBEMBE, 2016, p. 146).

xix Portaria n. 200, de 16 de março de 2020, da Reitoria/UFGD. Disponível em: https://portal.ufgd.edu.br/secao/coronavirus/deliberacao-do-coe-ufgd. Acesso em: 01 jun. 2020.

${ }^{\mathrm{xx}}$ Tais notas tiveram ampla circulação entre a comunidade acadêmica da UFGD, por meio das redes sociais. Contudo, não ficaram disponíveis on-line para consulta.

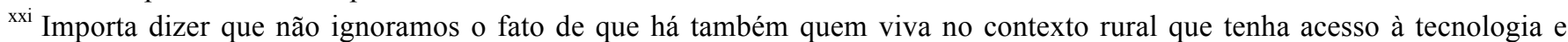
internet. Contudo, em algumas regiões rurais do país - como, p. ex., o Mato Grosso do Sul - isso ainda é restrito a poucos.

xxii Disponível em: https://www1.folha.uol.com.br/educacao/2020/05/pandemia-amplia-abismo-entre-escolas-publicas-eprivadas-no-brasil.shtml. Acesso em: 08 jul. 2020.

xxiii Disponível em: https://g1.globo.com/bemestar/coronavirus/noticia/2020/06/03/brasil-tem-32548-mortes-por-covid-19-dizministerio.ghtml. Acesso em: 03 jun. 2020.

xxiv Sobre isso ver: https://noticias.uol.com.br/saude/ultimas-noticias/redacao/2020/05/15/saiba-quem-e-general-pazuello-onovo-ministro-interino-da-saude.htm. Acesso em: 09 jul. 2020.

${ }^{x x v}$ Sobre isso consultar: SCHNEIDER, C. M.; TAVARES, M.; MUSSE, C. O retrato da epidemia de meningite em 1971 e 1974 nos jornais O Globo e Folha de S. Paulo. Revista Eletrônica de Comunicação, Informação e Inovação em Saúde, v. 9, n. 4, 2015.

xxvi Categoria associada ao processo de elitização dos acessos em saúde e que se aproximaria da dinâmica de expansão dos condomínios de luxo entre as camadas abastadas brasileiras, o que apontaria para uma visão privatizada do existir.

xxvii Disponível em: http://m.acervo.estadao.com.br/noticias/acervo,a-epidemia-do-silencio-texto-censurado-de-clovis-rossi-em1974,70002872715,0.htm. Acesso em: 07 jun. 2020.

xxvii Tanto Jessé Souza (2018) quanto Lilia Schwarcz (2019) questionam o mito que se construiu sobre a imagem do Brasil como um país miscigenado e, consequentemente, cordial. Nesse sentido, o trabalho de Gilberto Freyre teria sido fundamental.

xxix Disponível https://economia.ig.com.br/2019-05-22/numero-de-mulheres-que-chefiam-lares-sobe-pela-3-vez-mas-ainda-eminoria.html. Acesso em: 10 jun. 2020.

xxx Disponível em: http://www.onumulheres.org.br/noticias/mulheres-e-meninas-devem-estar-no-centro-dos-esforcos-deresposta-a-covid-19-apontam-mulheres-lideres/. Acesso em: 08 jul. 2020.

xxxi Disponível em: https://apublica.org/2020/05/em-duas-semanas-numero-de-negros-mortos-por-coronavirus-e-cinco-vezesmaior-no-brasil/. Acesso em: 09 jul. 2020.

xxxii Disponível em: https://www.brasildefato.com.br/2020/05/05/condicoes-precarias-de-moradia-dificultam-isolamentovertical-nas-periferias. Acesso em: 08 jul. 2020.

xxxiii Sobre isso, consultar: https://www.opantaneiro.com.br/aquidauana/vigilancia-sanitaria-orienta-indigenas-sobre-cuidadoscom-coronavirus/158363/. Acesso em: 09 jul. 2020.

xxxiv Fonte: Distrito Sanitário Especial Indígena de Mato Grosso do Sul - DIASI/DSEI-MS/SESAI/MS, 2020. Divulgado em 05 jun. 2020.

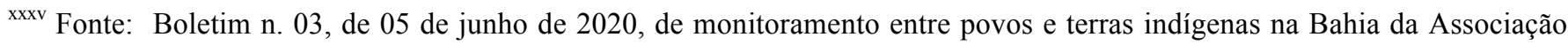
Nacional de Ação Indigenista - Anaí e do Movimento Unido dos Povos e Organizações Indígenas da Bahia - MUPOÍBA.

xxxvi Inclusive com a notificação de indígenas como pardos no quesito raça-cor, produzindo o falseamento do número de casos de indígenas afetados por covid-19 no país.

xxxvii Disponível em: https://cimi.org.br/coronavirus/. Acesso em: 07 jun. 2020.

xxxviii Disponível em: http://redehumanizasus.net/94812-onde-fala-a-bala-cala-a-fala. Acesso em: 08 jun. 2020. 